\title{
PERAN MAJELIS PELAYANAN SOSIAL (MPS) MUHAMMADIYAH UNTUK MENINGKATKAN KUALITAS PENGASUHAN ORANG TUA DALAM PELATIHAN GOOD PARENTING MELALUI MEDIA SOSIAL WHATS APP
}

\author{
Siti Nuraeni \\ Kober Az-Zahra Aisyiyah \\ diisstaa@gmail.com
}

Received: Juni, 2020; Accepted: September, 2020

\begin{abstract}
This research is motivated by the lack of competency in parenting care for MPS Muhammadiyah's children. The purpose of this study is: to reveal data about good parenting planning, the process of implementing good parenting, the results of implementing good parenting. The cornerstone of the theory in this study, researchers refer to several concepts, namely: understanding parenting and understanding good parentin. The approach used in this research is a qualitative approach using a case study method. Data collection techniques used are observation, interviews, documentation studies. This research is divided into three stages, namely long-term, medium-term and short-term planning, the implementation of which involves the caregivers of children in good parenting education and training programs while the results of this study are increased parental competence in parenting. The conclusion of this study is that good parenting education and training can increase the competence of parents in caring for their children so they can instill the love of parents for their children.
\end{abstract}

Keywords: Parenting, Good Parenting, MPS Muhammadiyah

\begin{abstract}
Abstrak
Penelitian ini dilatarbelakangi oleh lemahnya komptensi pengasuhan orang tua anak binaan MPS Muhammadiyah. Tujuan Penelitian ini adalah : untuk mengungkap data tentang perencanaan good parenting, proses pelaksanaan good parenting, dan hasil dan pelaksanaan good parenting. Landasan teori dalam penelitian ini, peneliti merujuk kepada beberapa konsep yaitu : pengertian pola asuh, dan pengertian good parenting. Pendekatan yang digunakan dalam penelitian ini adalah pendekatan kualitatif dengan menggunakan metoda studi kasus, teknik pengunpulan data yang digunakan adalah observasi, wawancara, studi dokumentasi. Penelitan ini di bagi menjadi tiga tahapan yaitu perencanaan jangka panjang, jangka menengah dan jangka pendek, pelaksanaanya yaitu mengikut sertakan para pengasuh anak dalam program pendidikan dan pelatihan good parenting sedangkan hasil dari penelitian ini adalah meningkatnya kompetensi orang tua dalam mengasuh. Kesimpulan dari penelitian ini bahwa pendidikan dan pelatihan good parenting dapat meningkatkan kompetensi orang tua dalam mengasuh anaknya sehingga dapat menanamkan kasih sayang orang tua untuk anaknya.
\end{abstract}

Kata Kunci: Pola asuh, Good Parenting, MPS Muhammadiyah

How to Cite: Nuraeni, S. (2020). Peran Majelis Pelayanan Sosial (Mps) Muhammadiyah Untuk Meningkatkan Kualitas Pengasuhan Orang Tua Dalam Pelatihan Good Parenting Melalui Media Sosial Whats App. Comm-Edu (Community Education Journal) 3 (3), 308-314.

\section{PENDAHULUAN}

Setiap anak lahir dengan membawa berbagai potensi, kemampuan, ciri dan sifat yang berbedabeda sehingga dalam perkembangannya akan selalu memiliki kelebihan dan kelemahan masing-masing. Pengertian anak menurut pasal 1 ayat (1) Undang-Undang Nomor 23 Tahun 
2002 Tentang Perlindungan Anak adalah seseorang yang belum berumur 18 (delapan belas tahun) termasuk anak yang masih dalam kandungan. Jadi secara fitrah, anak-anak sudah membawa berbagai potensi, kemampuan dan sifat baik yang ditanamkan oleh Allah SWT, namun ketika mereka tumbuh besar nanti itu akan tergantung dari bagaimana cara orang tua memberikan pendidikan dan pengasuhan kepada setiap anak yang lahir tersebut. Menjadi orang tua merupakan tugas mulia, apalagi bila dalam pernikahan tersebut dikaruniai buah hati tentu menjadi kebahagiaan. Namun ditengah perjalanan tidak bisa dipungkiri banyak keluarga mengalami faktor kerentanan dan kerapuhan keluarga, baik secara sosial, ekonomi, budaya, pendidikan dan agama.

Fakta dan analisa menunjukkan bahwa masih banyak kasus yang terjadi di dalam keluarga yang menyebabkan anak menjadi korban. Salah satunya disebabkan ketidak mampuan orang tua atau pengasuh utama untuk memberikan pengasuhan yang layak bagi setiap anak dan orang tua pun tidak mengetahui tentang fase perkembangan anak itu sendiri, padahal anak merupakan tanggung jawab dari orang tua atau pengasuh utamanya. Beberapa kasus yang terjadi akhirakhir ini yang kita tonton dan dengar di media, seperti fenomena gunung es. Contoh kasus yang terjadi adalah kekerasan yang dialami oleh anak baik itu kekerasan verbal, fisik, atau kekerasan seksual, data Kementrian Sosial Republik Indonesia pada tahun 2015 menyatakan bahwa sebanyak 4,5 juta jiwa mengalami kekersan fisik, kemudian 2,5 juta jiwa mengalami kekerasan emosional dan 1,5 juta jiwa mengalami kekerasan seksual (Sumber Kementrian Sosial Republik Indonesia). Selain itu banyak juga anak-anak yang menyimpang atau secara prilaku menunjukan sikap yang negatif. Adanya kasus atau kejadian yang menimpa anak di dalam keluarga sebetulnya kita menyadari namun tidak bisa berbuat banyak, dengan kondisi lingkungan dan zaman yang dinamikanya terus berubah. Begitu juga tidak banyak lembaga yang ditemui di masyarakat dapat membantu memperkuat pemahaman, perilaku, bahkan mekanisme dan sistem yang seharusnya bisa dibangun hingga di keluarga dan masyarakat.

Sebanyak 73,3 \% anak berusia 1-14 tahun di Indonesia mengalami kekerasan di dalam keluarga. Berdasarkan data yang di lansir oleh Global Report 2017: Ending Violence in Chilhood dalam (SindoNews.com.) Angka ini jelas sangat memprihatinkan dan tentunya harus mendapatkan perhatian pemerintah dan lembaga-lembaga terkait untuk mengurangi kekerasan terhadap anak yang semakin meningkat karena pengasuhan yang buruk seperti melakukan kekerasan terhadap anak mempunyai dampak negatif pada perkembangan sosial dan bahasa anak (Doherty, G. 1996).

Setiap orang tua menginginkan semua anaknya tumbuh menjadi anak yang baik atau jika anak mereka ada yang menyimpang maka keinginan orang tua anaknya bisa berubah, hanya saja hal diatas tidak dibarengi oleh sikap dan perubahan dari orang tua itu sendiri. Selain itu pengasuhan yang dilakukan masih besifat konvensional atau masih dibayang bayangi pengasuhan tahun 60an-70an dan tanpa mereka sadari itu membuat kelekatan orang tua dan anak tidak bisa berjalan dengan baik banyak contoh yang terjadi misalnya saat anak anak balita, orang tua banyak yang tidak mendengar apa yang dikatakan oleh anaknya, pada saat anak tersebut dewasa maka keadaan menjadi terbalik ketika orang tua yang bicara maka anak tidak mendengar perkataan orang tua artinya seorang anak tidak pernah gagal menjadi peniru yang baik, tetapi anak selalu gagal menjadi pendengar yang baik. Selain itu hal lain dari pola pengasuhan yang kurang tepat yang dilakukan orang tua, salah satu contoh nyata dalam kehidupan anak adalah banyak anak hidup membosankan karena dalam enam hari menjalani rutinitas dunia pendidikan, sejatinya dunia anak diisi dengan bermain. Namun karena belajar 
dianggap orang tua sebagai kebutuhan anak, seringkali orang tua terhipnotis dengan selembar kertas rapot dan melupakan sisi sosial kehidupan anak yang lainnya.

Orang tua seharusnya mampu memahami karakter dari setiap anaknya, artinya mampu menumbuhkan benih-benih kebaikan yang sudah ada dalam diri anak hingga berkembanglah prilaku positif, termasuk perilaku mandiri dan akhlaqul karimah. Inilah sesungguhnya peran yang harus dilakukan oleh orang tua kepada anaknya. Sebagaimana menumbuhkan tanaman, untuk bisa menumbuhkan prilaku positif pada anak tentunya melalui proses. Proses inilah nilai ibadahnya karena dalam proses pengasuhan yang baik, ada kesabaran, kerja keras, belajar, contoh prilaku, do'a dan tawakal "Abis wiguna dalam bukunya curahan hati ananda". Ada satu pesan singkat yang luar bisa dari umar bin kkhatab "Didiklah anak sesuai dengan zamannya" Sudahkah anda memahami kondisi tantangan zaman yang akan dihadapi anak-anak di masa depan? Mari kita tumbuhkan benih-benih kebaikan yang telah ditanamkan Allah dalam diri anak-anak kita dengan baik dan secara benar, bukan menanamkan bibit baru yang belum tentu tepat, bahkan bisa mematikan benih-benih kebaikan yang sudah ada.

Adanya kasus atau kejadian yang menimpa anak di dalam keluarga sebetulnya kita menyadari namun tidak bisa berbuat banyak, dengan kondisi lingkungan dan zaman yang dinamikanya terus berubah. Begitu juga tidak banyak lembaga yang ditemui di masyarakat dapat membantu memperkuat pemahaman, perilaku, bahkan mekanisme dan sistem yang seharusnya bisa dibangun hingga di keluarga dan masyarakat. Melihat fakta-fakta yang ada di lingkungan, hal ini sejalan dengan adanya Majlis Pelayanan Sosial Muhammadiyah yang merupakan salah satu majelis yang berada di bawah pimpinan Muhammadiyah dan bergerak di bidang dakwah serta perlindungan dan pelayanan sosial terhadap masyarakat sekitar, dimana Majlis Pelayanan Sosial ini membawahi Lembaga Kesejahteran Sosial Asuhan Anak (LKSA) Panti Sosial Asuhan Anak (PSAA) Kuncup Harapan. Melalui Majlis Pelayanan Sosial ini dapat diksanakan program/pelatihan good parenting untuk meningkatkan kualitas pengasuhan orang tua.

Parenting merupakan proses pembelajaran pengasuhan interaksi antara orang tua dan anak yang meliputi aktivitas memberi petunjuk, memberi makan, memberi pakaian, melindungi anak saat mereka tumbuh berkembang. Parenting education merupakan pendidikan yang berkaitan dengan cara atau teknik pengasuhan atau mengasuh anak saat mereka tumbuh berkembang. Parenting education ini bertujuan meningkatkan pengetahuan dan keterampilan orang tua dalam melaksanakan perawatan dan pengasuhan anak-anak mereka, serta meningkatkan kesadaran orang tua atau anggota keluarga lain sebagai pendidik yang pertama dan utama.

Berdasarkan hal tesebut, maka diperlukannya program/pelatihan good parenting di Panti Asuhan Kuncup Harapan karena melihat fakta yang ada dan faktor yang menyebabkan orang tua memasukan anaknya ke dalam panti asuhan yaitu karena bagi sebagian orang tua panti asuhan menjadi tempat pelarian keluh kesah orang tua yang ingin bebas dalam memberikan kebutuhan ekonomi, pengasuhan, serta pendidikan bagi anaknya, dengan dilaksanankannya good parenting bertujuan agar memberi pengetahuan bagi orang tua dalam memberikan pengasuhan kepada anaknya. Hal inilah yang membuat peneliti tertarik untuk mengatahui bagaimana Peran Majlis Pelayanan Sosial (MPS) Muhammadiyah dalam Program Good Parenting untuk Meningkatkan Kualitas Pengasuhan Orang Tua Melalui Media Sosial Whats App. 


\section{LANDASAN TEORI}

Menurut Mustofa Kamil (2010: 33) bahwa ciri-ciri Pendidikan Luar Sekolah jika dilihat dari segi pengendalian program, karateristik pendidikan luar sekolah adalah dilakukan oleh pelaksana program dan peserta didik serta menggunakan pendekatan yang lebih bersifat demokratis. Good Parenting merupakan suatu bentuk Pendidikan Luar Sekolah karena memiliki karateristik dan ciri yang sama dalam programnya yaitu dilaksanakan oleh pelaksana program bersama keluarga dan menggunakan pendekatan yang demokratis.

Pola asuh merupakan bagian dari proses pemeliharaan anak dengan menggunakan teknik dan metode yang menitikberatkan pada kasih sayang dan ketulusan cinta yang mendalam dari orangtua/guru dengan dua dimensi yaitu; hubungan emosional orangtua/ guru dan anak, serta cara orangtua/guru mengontrol perilaku anak (Mohammad Takdir Ilahi, 2013:134).

Menurut pendapat dari Jumiatmoko (2016) WhatsApp Messenger merupakan bagian dari sosial media. Sosial media merupakan aplikasi berbasis internet yang memungkinkan setiap penggunanya dapat saling berbagi berbagai macam konten sesuai dengan fitur pendukungnya. WhatsApp Messenger merupakan teknologi popular yang sangat potensial untuk dimanfaatkan sebagai alat pembelajaran. Al Saleem (dalam Jumiatmoko, 2016) menambahkan bahwa dalam WhatsApp Messenger terdapat Whatsapp Group yang mampu membangun sebuah pembelajaran yang menyenangkan terkait berbagai topik diskusi yang diberikan oleh pengajar.

Menurut Pendapat dari Trisnani (2017) Whats App paling dominan digunakan saat ini, Whats App telah dimanfaatkan oleh tokoh masyarakat untuk berkomunikasi dalam menyampaikan pesan kepada sasarannya. Saat ini meskipun masih berkomunikasi secara langsung tokoh masyarakat memanfaatkan Whats App sebagai media komunikasi dalam penyampaian pesan. Informasi yang disampaikan lebih efektif dan merupakan kepuasan tersendiri karena dengan menggunakan teknologi informasi Whats App pesan lebih cepat diterima oleh sasaran. Dalam hal ini pesan yang disampaikan berupa informasi tentang parenting dari penyelenggara pelatihan kepada orang tua yang sebelumnya mengikuti pelatihan good parenting dengan memanfaatkan group Whats App sebagai media pemberian informasi tentang pengasuhan orang tua terhadap anak.

\section{METODE}

Metode yang akan digunakan dalam penelitian ini adalah metode kualitatif dengan menggunakan pendekatan deskriptif analitis. Menurut Sugiyono, (2003 : 11) menyatakan bahwa : "Metode penelitian deskriptif adalah "Penelitian yang dilakukan untuk mengetahui nilai variabel mandiri, baik satu variabel atau lebih (independen) tanpa membuat perbandingan, atau menghubungkan antara variabel satu dengan variabel yang lain". Menurut Poerwandari (1998) penelitian kualitatif adalah penelitian yang menghasilkan dan mengolah data yang sifatnya deskriptif, seperti transkripsi wawancara, catatan lapangan, gambar, foto rekaman video dan lain-lain. Dalam penelian kualitatif perlu menekankan pada pentingnya kedekatan dengan orang-orang dan situasi penelitian, agar peneliti memperoleh pemahaman jelas tentang realitas dan kondisi kehidupan nyata. (Patton dalam Poerwandari, 1998).

Penelitian ini dilakukan di Lembaga Kesejahteraan Sosial Anak Panti Sosial Asuhan Anak Kuncup Harapan yang beralamat di Jl. Garunggang Kulon no. 179/65 RT. 06 RW. 11 Sukabungah, Kec. Sukajadi, Kota Bandung, Jawa Barat 40162. Teknik pengumpulan data dilakukan dengan wawancara, observasi dan dokumentasi. Populasi pada penelitian ini adalah 
orang tua dari anak-anak di Panti Asuhan Kuncup Harapan serta tutor sedangkan untuk sampel penulis mengambil 5 orang tua dan 2 tutor.

Teknik analisis data yang dilakukan dalam penelitian ini menggunakan tahapan-tahapan yang dikemukakan oleh (Marshall dan Rossman dalam Kabalmay, 2002) yang meliputi pengorganisasian data, pengelompokkan berdasarkan kategori, tema dan pola jawaban, kemudian menguji asumsi atau permasalah yang ada terhadap data, mecari alternatif penjelasan bagi data dan yang terakhir menulis hasil penelitian.

\section{HASIL DAN PEMBAHASAN}

\section{Hasil}

Hasil dari penelitian yang dilakukan yaitu Majelis Pelayanan Sosial (MPS) Muhammadiyah melaksanakan tiga serangkaian kegiatan dalam program pelatihan good parenting, dimana kegiatan pertama diawali dengan perencanaan pelatihan, kemudian pelaksanaan pelatihan dan menganalisis hasil dari pelatihan selanjutnya peserta pelatihan di gabung dalam suatu group Whats App yang bertujuan agar para orang tua yang dikut sertakan dalam pelatihan good parenting ini tidak hanya sekali saja dalam mendapatkan bimbingan mengenai cara pengasuhan yang baik untuk anak tetapi dapat berlanjut dengan diberikan bimbingan melalui group whats app selain itu dengan adanya group whats app ini silaturahmi antara Majelis Pelayanan Sosial (MPS) Muhammadiyah selaku lembaga yang menyelenggarkaan pelatihan, dengan orang tua sebagai peserta pelatihan tidak terputus.

Majelis Pelayanan Sosial (MPS) Muhammadiyah memberikan peran yang sangat baik dalam meningkatkan kualitas pengasuhan orang tua terhadap anak melalui program pelatihan good parentig yang di laksanakan di Panti Asuhan Kuncup Harapan, hal ini terlihat dari adanya perubahan pola pengasuhan orang tua, setelah mengikuti pelatihan para orang tua mengetahui bagaimana memberikan pengasuhan yang baik bagi anak di dalam keluarga, para orang tua juga lebih memahami mengenai fase-fase perkembangan anak dan tentunya para orang tua tidak lagi melakukan pengasuhan terhadap anak dengan cara kekerasan karena para orang tua sangat memahami pentingnya mengasuh anak dengan baik.

\section{Pembahasan}

Majelis Pelayanan Sosial Muhammadiyah merupakan suatu lembaga pelayanan kesejahteraan sosial yang dulu di bawah naungan Majelis Kesehatan dan Kesejahteraan Masyarakat PCM Sukajadi dan sekarang menjadi tanggung jawab Majelis Pelayanan Sosial (MPS) Pimpinan Cabang Muhammadiyah Sukajadi Kota Bandung. Majelis Pelayanan Sosial Muhammadiyah tidak hanya memberikan pelayanan kepada anak asuh, melainkan mendidik dengan berbagai disiplin ilmu pengetahuan yang dapat mengembangkan diri anak asuh baik dari segi jasmani maupun rohani sesuai dengan ilmu pengetahuan dan ajaran agama sehingga menjadi anak yang mandiri dan memiliki masa depan yang cerah. Di tunjang dengan pendidikan formal yang dibekali keterampilan dan pembinaan keagamaan untuk "mewujudkan pelayanan sosial yang mandiri, berprestasi dan berakhlakulkarimah." sesuai dengan pendapat yang di kemukakan oleh Ahmad Dahlan (dalam Juniawandahlan, 2017) dalam pemikirannya mengenai pendidikan islam di indonesia yang mengemukakan bahwa "Pendidikan yang utuh adalah pendidikan yang berkesinambungan antara perkembangan mental dan jasmani, keyakinan dan intelek, perasaan dengan akal pikiran, serta antara dunia dan akhirat" 
Perencanaan good parenting untuk peningkatan Pola asuh orang tua terhadap anak dalam hal pendidikan, pengasuhan dan perlindungan anak agar bisa memahami faktor-faktor pengasuhan anak, karakteristik anak, permasalahan yang menghambat perkembangan anak, serta merupakan wujud komunikasi orang tua dan anak sehingga orangtua terlibat dalam emosional anak. Berkaitan dengan hal tersebut berdasarkan hasil wawancara dengan Ketua Majlis Pelayanan Sosial dalam rangka perencanaam Good Parenting untuk meningkatkan kualitas pengasuhan anak beliau memaparkan bahwa perencanaan kegiatan good parenting Merupakan Proses program majelis pelayanan sosial Muhammadiyah dimulai dengan mengadakan konsolidasi dan musyawarah antara pengurus dengan pihak yang terkait untuk menyamakan pengertian, pemahaman dan kebersamaan melalui pertemuan-pertemuan sebagaimana yang di kemukakan oleh Cunningham dalam Usman (2008:60) menyatakan bahwa perencanaan adalah menyeleksi dan menghubungkan pengetahuan, fakta, imajinasi dan asumsi yang bertujuan untuk memvisualisasi masa yang akan datang dan memformulasi hasil yang diinginkan, urutan kegiatan yang diperlukan dan perilaku dalam batas-batas yang dapat diterima dan digunakan dalam penyelesaian. Menurut responden perencanaan kegiatan good parenting hampir seluruhnya sudah dilaksanakan secara maksimal dan hasilnya cukup baik.

Pelaksanaan pelatihan Good Parenting merupakan tindak lanjut dari proses perencanaan pembinaan orang tua anak asuhan luar panti. Good Parenting yang dilakukan secara sungguh - sungguh oleh Majelis Pelayanan Sosial Muhammadiyah akan membawa dan menentukan keberhasilan, yang kemudian di kembangkan serta diadakan pembinaan secara rutin maka kualitas orang tua dalam hal pengasuhan akan semakin jelas arah dan tujuannya dalam membina, mendidik dan pengawasan terhadap anak, disamping peningkatan kualitas dan terbentuknya keluarga yang harmonis yang telah di rencanakan oleh Majelis Pelayanan Sosial Muhammadiyah. Selanjutnya berdasarkan hasil pengamatan dan wawancara dalam pelaksanaan kegiatan good parenting Majlis Pelayanan Sosial Muhammadiyah melakukan Langkah-langkah penting di dalam mempersiapkan materi untuk sebuah pelatihan good parenting adalah sebagai berikut: 1) Menentukan dan memprioritaskan isi/muatan materi good parenting. 2) Menentukan metode dan media good parenting. 3) Menentukan kebutuhan waktu Biasanya dalam menentukan perkiraan kebutuhan waktu didasarkan pada skala prioritas seperti yang dikemukakan oleh Browne dan Wildavsky bahwa pelaksanaan merupakan suatu perluasan aktivitas yang saling menyesuaikan.

Hasil dari wawancara seputar pemahaman tentang arti dan konsep serta ciri-ciri keluarga sakinah responden mengungkapkan bahwa pengertian keluarga adalah bagian terkecil masyarakat terdiri dari suami, istri dan anak yang terikat dengan pernikahan. Pendapat responden mengenai ciri-ciri keluarga sakinah adalah menjalankan agama dengan baik, saling mencintai, menyayangi dan harmonis dalam berkeluarga, baik dalam bergaul dengan masyarakat dan bertetangga, suasana dalam keluarga penuh ketentraman, tenang dan nyaman. Pendapat responden tersebut sejalan dengan pengertian keluarga yang dikemukakan oleh Sugeng Iwan dalam wikipedia yang menyatakan bahwa "Keluarga adalah unit terkecil dari masyarakat yang terdiri atas kepala keluarga dan beberapa orang yang terkumpul dan tinggal di suatu tempat di bawah suatu atap dalam keadaan saling ketergantungan." Salah satu dampak setelah mengikuti kegiatan Good Parenting menurut responden adalah interaksi diantara orang tua dan anak menjadi lebih baik, komunikasi dalam keluarga lebih kondusif. Pemahaman peran individu dalam keluarga menurut responden harus saling menghormati dan menghargai, istri harus mengerti terhadap suami dan anak-anak, tidak egois dan mendikte dan komunikasi di antara anggota keluarga sangat penting. Selain itu setelah mengikuti kegiatan Good parenting kondisi pemahaman kehidupan beragama menurut responden ada peningkatan dalam ibadah, pengetahuan dan meningkatkan keimanan kepada Allah SWT. Pentingnya interaksi melalui 
komunikasi diantara anggota keluarga maupun dilingkungan masyarakat ini sesuai dengan pendapat yang dikemukakan oleh (Dedy Mulyana, 2003) yang menyatakan bahwa Komunikasi sangat penting dan wajib dilakukan, Orang yang tidak berkomunikasi dengan manusia bisa dipastikan akan tersesat karena ia tidak bisa menaruh dirinya dalam lingkungan sosial.

\section{KESIMPULAN}

Berdasarkan uraian hasil penelitian di atas maka dapat diambil kesimpulan bahwa peran Majelis Pelayanan Sosial (MPS) Muhammadiyah telah melaksanakan pelatihan good parenting yang bertujuan untuk meningkatkan kualitas pengasuhan orang tua terhadap anak. Pelatihan ini di dukung juga dengan pemanfaatan media sosial whats app paska pelaksanaan pelatihan good parenting.

\section{DAFTAR PUSTAKA}

Doherty, G. 1996. Dalam Modul Pelatihan : Perlindungan Anak dan Good Parenting. Jakarta selatan: Save The Children

Kamil, Mustofa. 2010. Model Pendidikan Dan Pelatihan (Knsep dan Aplikasi). Bandung: Penerbit Alfabeta

Poerwandari, E. K 1998 Pendekatan Kualitatif Dalam Penelitian Psikologi. Jakarta : LPSP3 Psikologi UI

Ilahi, Mohammad Takdir. (2013) Quantum Parenting : Kiat Sukses Mengasuh Anak Secara Efektif dan Cerdas. Jogjakarta : Ar-Ruzz Media

Sugiyono, 2011. Metodologi Penelitian Kuantitatif dan Kualitatif dan R\&D. Bandung: Penerbit Alfabeta

Nurdin dan Usman (2004:70) Dalam Modul Pelatihan : Perlindungan Anak dan Good Parenting Jakarta: PT. Raja Grafindo Persada

Mulyana, Dedy. 2003 Metode Penelitian Kualitatif Paradigma Baru Ilmu Komunikasi Dan Ilmu Sosial Lainnya. Bandung : Remaja Rosdakarya

Kabalmay. (2002). Designing Qualitatitative Research. London: Sage Publication

Juniawandahlan. 2017. Ahmad Dahlan Dalam Pemikirannya Mengenai Pendidikan Islam di Indonesia. (Online). Tersedia https://kebudayaan.kemdikbud.go.id/mkn/ahmad-dahlandalam-pemikirannya-mengenai-pendidikan-islam-di-indonesia/. Diakses pada tanggal 8 Februari 2020

A Syahrin, 2017. BAB II Landasan Teori (Online). Tersedia : https://repository.widyatama.ac.id/xmlui/bitstream/handle/123456789/8800/Bab\%202.pdf ?sequence $=10$. Diakses pada tanggal 8 februari 2020

Jumiatmoko. (2016). WHATSAPP MESSENGER DALAM TINJAUAN MANFAAT DAN ADAB. Wahana akademika volume 3 no. 1, 51-66

Trisnani. (2017). PEMANFAATAN WHATS APP SEBAGAI MEDIA KOMUNIKASI DAN KEPUASAN DALAM PENYAMPAIAN PESAN DIKALANGAN TOKOH MASYARAKAT. Jurnal Komunikasi, Media dan Informatika volume 6 no. 3, 1-12 